Industrial Health, 1975, 13, 151

\title{
MUSCULAR BURDEN DERIVED FROM DYNAMIC LOADING
}

\author{
PART 1. RESPONSE TO CONTINUOUS DYNAMIC LOADING \\ OF WRITING PERFORMANCE IN THE HAND-ARM- \\ SHOULDER SYSTEM
}

\author{
Tadayoshi SAKURAI and Toshisuke MIWA \\ Department of Environmental Health, Medical School, Kurume University, \\ Asahi-machi, Kurume, Fukuoka, and National Institute of Industrial \\ Health, Kizuki-Sumiyoshi, Nakahara-ku, Kawasaki
}

(Received November 10, 1975)

\begin{abstract}
In order to analyse writing work which was considered to be continuous burdens of the hand-arm-shoulder system, the electromyogram(EMG) of the shoulder and the arm on the writing hand side using surface electrodes and the writing pressure were observed during writing performance. Factors associated with writing such as writing tools (a ball-point pen and a pencil of hardness of HB) diameters of penholder ( $7 \mathrm{~mm}$ and $11 \mathrm{~mm}$ ), number of sheets of paper (1 and 3 ) and sex difference were analysed quantitatively with the experimental design method. Above all, the muscular tension and the writing pressure during a 20 min writing were examined. The subjects were asked to write, through hearing from a loud-speaker, one Japanese "kana" leter per 1 sec under the usual writing pressure or the writing pressure above the given minimum value of $0.13 \mathrm{~kg}$.

It can be concluded that the burden of muscles of the arm and the shoulder caused by the pencil is lighter than that by the ball-point pen and the burden of shoulder muscles indicates spectrum change in the low frequency components of EMG below $20 \mathrm{~Hz}$ even in $20 \mathrm{~min}$ continuous writing. The larger diameter penholder and the thicker sheets of paper promote increase of muscular tension which may induce muscular fatigue. The writing pressure which shows spectrum of 1-7 Hz also endorses these findings.
\end{abstract}

Writing work in business offices in the european countries has been highly mechanized introducing electric typewriters and electronic copying machines. On the contrary, the writing work in Japan has still been made by the hand due to unique Japanese letters. For the purpose of meeting the aim, the new business tools have been developed such as ball-point pens and copy slips with pressure sensing ink.

Workers mostly female in Japan who have been engaged in writing work for a long time, however, complain frequently of the stiff shoulder, numbness, pains and dullness of the arms, the hands and the fingers, and of cool feeling and insensibility of the fingers. 


\section{T. SAKURAI AND T. MIWA}

These symptoms are classified as one of the neck-shoulder-arm syndrome.

In previous researches regarding writing performance, the graphoanalysis has been developed in the psychological field.1,2) The improvement of writing tools has been studied for the purpose of the easy handling and good writing., ${ }^{3,4)}$ There have been a few papers published about writing work from the viewpoints of muscular tension of the hands and the arms. Among them, one paper ${ }^{5)}$ described the findings of increase of the muscular tension of the arm in the writing work and of the correlation between the gripping force of a pen holder and the writing pressure on a paper, especially, of the optimum gripping force with regard to a sizable diameter of the pen holder. Another paper ${ }^{6)}$ reported that the muscular tension of the hand increased with increase of number of sheets of copy slip and in addition it depended upon the kinds of the writing tools such as a ball-point pen or a sharp marker pen.

In consideration of these results, we planned the new experiments to investigate main factors and their interactions offering influence on the muscular tension during writing performance with the help of experimental design method.

\section{Experimental Procedures}

The writing pressure and the electromyogram (EMG) were observed during the writing work. The writing pressure was measured by a $25 \times 5.5 \times 0.3 \mathrm{~cm}^{3}$ aluminum plate under which two force pickups were set at the positions of $1 / 4$ and $3 / 4$ of its length on the central line of longer side of the rectangular plate. A thin film of poly-fluorovinyliden with the electro-strictive effect was used as the detector of the force, which was sandwiched between two sheets of metal plate. The size of the force pickup was $12 \mathrm{~mm}$ in diameter and $3 \mathrm{~mm}$ in thickness. The force detecting plate mentioned above was set on an aluminum plate $\left(25.5 \times 31.5 \mathrm{~cm}^{2}\right)$ and on its unoccupied area by another pieces of aluminum plate were set. To calibrate the writing pressure, the force detecting plate on which a certain mass was loaded was set on a vibration table of electrodynamic type and sinusoidal vibration was imposed from 2 to $50 \mathrm{~Hz}$ at the constant acceleration, which was in the available frequency range of the force detector. The output voltage of the force pickup was recorded by a high speed level recorder with the available frequency range between 2 and $20,000 \mathrm{~Hz}$. We found that this force detecting plate had the flat frequency response in this frequency range within $\pm 2 \mathrm{~dB}$, and the difference of the output voltage caused by different position of pressing on the detecting plate was also within $\pm 1.5 \mathrm{~dB}$.

Generally speaking, a piece of information for writing is conveyed to the brain through visual or auditory sensation and is converted to signals to drive the arms, the hands, and the fingers in cooperation with the feedback systems in the muscles of shoulders, arms, hands and fingers. The muscles of the shoulders and the arms are considered to be the parts most influenced in the body by the writing work. The EMG, therefore, was observed on the trapezius and the forearm flexor (flexor) on the writing 


\section{MUSCULAR BURDEN DERIVED FROM DYNAMIC LOADING I}

hand side using surface electrodes. The signals of the EMG with the frequency range from 2 to $500 \mathrm{~Hz}$ and the writing pressure were amplified and recorded with a datarecorder, of which the available frequency range was from $0.05 \mathrm{~Hz}$, to $650 \mathrm{~Hz}$, under watching syncro-scope to avoid satulation of the input signals into the amplifiers of the recorder. The frequency analysis of the writing pressure and the EMG was made with a band-pass filter, and a high speed level recorder was employed to record their rectified output voltages. The data-processing techniques for the acoustics were used to the signals of EMG because of its wide frequency range and randomness in time hystory. A root-mean-square value ( $\mathrm{rms}$ in $\mathrm{dB}$ ) could be shown with the level-recorder of which a time constant could arbitrarily be changed. The writing speed was set at $16 \mathrm{~mm} / \mathrm{sec}$.

The following factors were investigated: writing speeds, writing pressures, working time, kinds of writing tools, diameters of pen-holders, number of sheets of paper and sex difference. The writing speed was difficult to be controlled arbitrarily for the long period of time. It was, therefore, controlled by see-writing and hear-writing. The former was that the subject was asked to write simple chinese characters with arbitrary speed by seeing the paper boad on which the words were written, and the latter was hear-writing in which the subject was asked to write the Japanese cursive "kana" characters with a constant speed of a letter per sec through hearing of the reading voice from a speaker. While the writing speed could individually be controlled in the seewriting, the speed could not be controlled in the hear-writing. The writing pressure was varied in free-writing and control-writing as follows: the actual copy writing work introduced the control-writing in which the writing pressure was controlled by the subject who was watching the meter of the writing pressure to keep the pressure above $0.13 \mathrm{~kg}$. In the free-writing, the subject wrote the letter under the arbitrary writing pressure for the purpose of comparison with the control-writing. The writing was carried out during $20 \mathrm{~min}$ in the principal experiment.

As writing tools, a ball-point pen and a pencil were employed because the use of ball-point pen had arisen sometimes hygienic problems among workers and the pencil with a hardness of $\mathrm{HB}$ and with a sharp top was used for comparison. The diameters of pen-holders were changed by $7 \mathrm{~mm}$ and $11 \mathrm{~mm}$ of a hexagon to investigate the suitable size. Number of sheets of paper was selected as 3 to simulate the copy work and as 1 for comparison. The sex difference among subjects in the writing was also checked.

\section{Setting of experimental conditions (see-writing and hear-writing)}

As the preliminary experiments, we examined two writing methods of see-writing and hear-writing to check the effect of writing speed on the EMG. The subjects were asked to continue the see-writing for $10 \mathrm{~min}$ and after a $5 \mathrm{~min}$ recess to continue the hear-writing for $10 \mathrm{~min}$ so that the effect of the former experiment might not remain. They wrote each letter in a $7^{2} \mathrm{~mm}^{2}$ area on a sheet of standard type manuscript paper with the usual ball-point pen. 


\section{T. SAKURAI AND T. MIWA}

It was observed that the EMG on the trapezius and the flexor depended upon the writing speed and the working times as shown in Figs. 1, a and b, in which each curve was the average of 8 subjects. Every rectified voltage of the EMG for the individual subject is normalized as 1 by the starting voltage on the see-writing. On the trapezius in the see-writing in Fig. 1, a, the level increases to about $50 \%$ within about $2 \mathrm{~min}$

RECTIFIED VOLTAGE OF THE EMG ON TRAPEZIUS

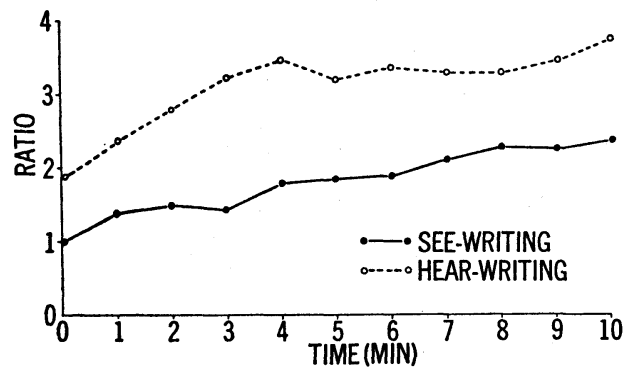

RECTIFIED VOLTAGE OF THE EMG ON FLEXOR

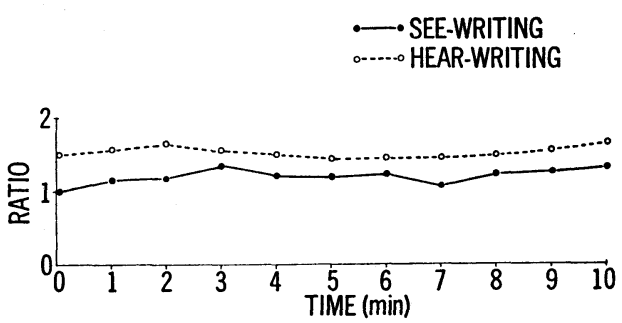

Fig. 1, $a$ and $b$ : The rectified voltages of EMG for the see-writing and the hear-writing.

The values observed are the averages of 8 subjects ( 4 males and 4 females) under the same experimental conditions. Every rectified voltage of the EMG is normalized as 1 at the starting voltage.

$a$; On the trapezius muscles and b; On the forearm flexor muscles (flexor).

after starting of the wrok and then shows the tendency of a gentle slope till the end of the experiment. On the other hand, in the hear-writing, the level reaches 3 fold within $4 \mathrm{~min}$ and this level is kept till the end of experiment. This fact denotes that the trapezius has been severely used in the hear-writing even in $10 \mathrm{~min}$ as compared with the see-writing.

On the EMG of the flexor in Fig. 1, b, the rectified value has been almost kept constant during the entire working time in both the writings. It can be explained that the load of the muscles seems small and constant. Even in the case of the flexor, the hear-writing can be said to be severer than the see-writing because the muscular tension is higher in the hear-writing than in the see-writing. On the principal examination, emphasis was shifted to the hear-writing instead of the see-writing from the viewpoint of muscular tensions.

\section{Experimental design methods}

The main factors with two levels such as the ball-point pen or the pencil (A), 7 or $11 \mathrm{~mm}$ diameter of the pen-holders (B), 1 or 3 sheets of paper (C) and subjects of males or females (D) were tested using orthogonal array table of $L_{8}\left(2^{7}\right)$ type with the repetition in the experimental design method. The concrete layout for the factors is shown in Table 1. We wanted to investigate the factors $\mathrm{A}, \mathrm{B}$ and $\mathrm{C}$ and the interaction between 


\section{MUSCULAR BURDEN DERIVED FROM DYNAMIC LOADING I}

Table 1. Orthogonal array table $\mathrm{L}_{8}\left(2^{7}\right)$

\begin{tabular}{l|c|ccccccc}
\hline Entry & & 1 & 2 & 3 & 4 & 5 & 6 & 7 \\
\hline Number of & 1 & 0 & 0 & 0 & 0 & 0 & 0 & 0 \\
experiment & 2 & 0 & 0 & 0 & 1 & 1 & 1 & 1 \\
& 3 & 0 & 1 & 1 & 0 & 0 & 1 & 1 \\
& 4 & 0 & 1 & 1 & 1 & 1 & 0 & 0 \\
& 5 & 1 & 0 & 1 & 0 & 1 & 0 & 1 \\
& 6 & 1 & 0 & 1 & 1 & 0 & 1 & 0 \\
& 7 & 1 & 1 & 0 & 0 & 1 & 1 & 0 \\
& 8 & 1 & 1 & 0 & 1 & 0 & 0 & 1 \\
\hline & & $\mathrm{A}$ & $\mathrm{B}$ & $\mathrm{A}$ & $\mathrm{C}$ & $\mathrm{A}$ & $\mathrm{B}$ & $\mathrm{A}$ \\
& & & & $\times$ & & $\times$ & $\times$ & $\times$ \\
& & & & $\mathrm{B}$ & & $\mathrm{C}$ & $\mathrm{C}$ & $\mathrm{B}$ \\
& & & & & & & & $\times$ \\
& & & & & & & & 品 \\
& & & & & & & & $\mathrm{D}$ \\
\hline
\end{tabular}

\begin{tabular}{l|l|l}
\hline \multicolumn{3}{|c}{ Factors and levels } \\
\hline $\mathrm{A}$ & 0 & Ball-point pen \\
\cline { 2 - 3 } & 1 & Pencil (HB) \\
\hline $\mathrm{B}$ & 0 & $7 \mathrm{~mm}$ diameter of pen holder \\
\cline { 2 - 3 } & 1 & $11 \mathrm{~mm}$ diameter of pen holder \\
\hline $\mathrm{C}$ & 0 & a sheet of paper \\
\hline $\mathrm{D}$ & 0 & 3 sheets of paper \\
\hline $\mathrm{d}$ & 1 & female \\
\hline
\end{tabular}

$\mathrm{A} \times \mathrm{B}, \mathrm{A} \times \mathrm{C}$ and $\mathrm{B} \times \mathrm{C}$. The interaction among three factors of $\mathrm{A} \times \mathrm{B} \times \mathrm{C}$ was neglected and that column was used for the sex of the subjects (D). The analysis of variance was automatically calculated by a mini-computer. ${ }^{8)}$ In the repetition of experiment the date (d) was taken as the block factor. ${ }^{9)}$ The statistical models for the observed values of EMG and the writing pressures are constructed as

$$
\mathrm{V}_{\text {obs }}=\mu+\mathrm{A}+\mathrm{B}+\mathrm{C}+\mathrm{D}+\mathrm{d}+\mathrm{A} \times \mathrm{B}+\mathrm{A} \times \mathrm{C}+\mathrm{B} \times \mathrm{C}+\mathrm{e}
$$

where $\mathrm{V}_{\text {obs }}$ : observed values of EMG or writing pressure, $\mu$ : their averages and e: error. The confidence range was calculated with the observed values for each factor. ${ }^{9)}$ The rectified level of the EMG depends upon location of the surface electrodes on the body and their distance. For convenience to the statistical calculation, the level of the EMG in the writing is normalized with the level of EMG generated from the same electrodes when a weight of $1 \mathrm{~kg}$ was horizontally held on the palm of one hand within $20 \mathrm{sec}$. For the flexor, the weight was held when the elbow joint was bent rectangularly. For the trapezius, the subject was asked to hold horizontally the arm straightforward at the same level of his shoulder and to keep the hand with the palm side up, on which the weight was set. This check was made just after the end of the writing performance and besides for linearity test the weight was varied from 0.5 to $2 \mathrm{~kg}$. The output voltage of EMG for holding of the $1 \mathrm{~kg}$ weight for each subject was taken as $30 \mathrm{~dB}$, which was adopted as the standard of the voltage of the EMG in the writing.

About the writing pressure, the minimum overall level (dB) among the subjects tested was adopted a the standard to normalize the observed values and the difference in $\mathrm{dB}$ was converted to the real quantity for variance analysis. The experiments under the condition of the control writing pressure and the free-writing pressure were repeated twice at different dates to check the reproducibility. The experiment was carried out in a $2^{3} \mathrm{~m}^{3}$ electric shield room on more than different 20 subjects chosen from members of our institute. 


\section{T. SAKURAI AND T. MIWA}

\section{Results AND Discussion}

Frequency spectra of EMG

The frequency spectra of the EMG were observed on the recorded data on 1-4 min and 17-20 min after starting of the experiment which are called the spectra of $V_{1}$ and $V_{20}$. Their overall values are indicated as $A_{1}$ and $A_{20}$. The typical EMG spectra on 4 subjects are shown in Figs. 2 and 3. Although each subject was tested under somewhat
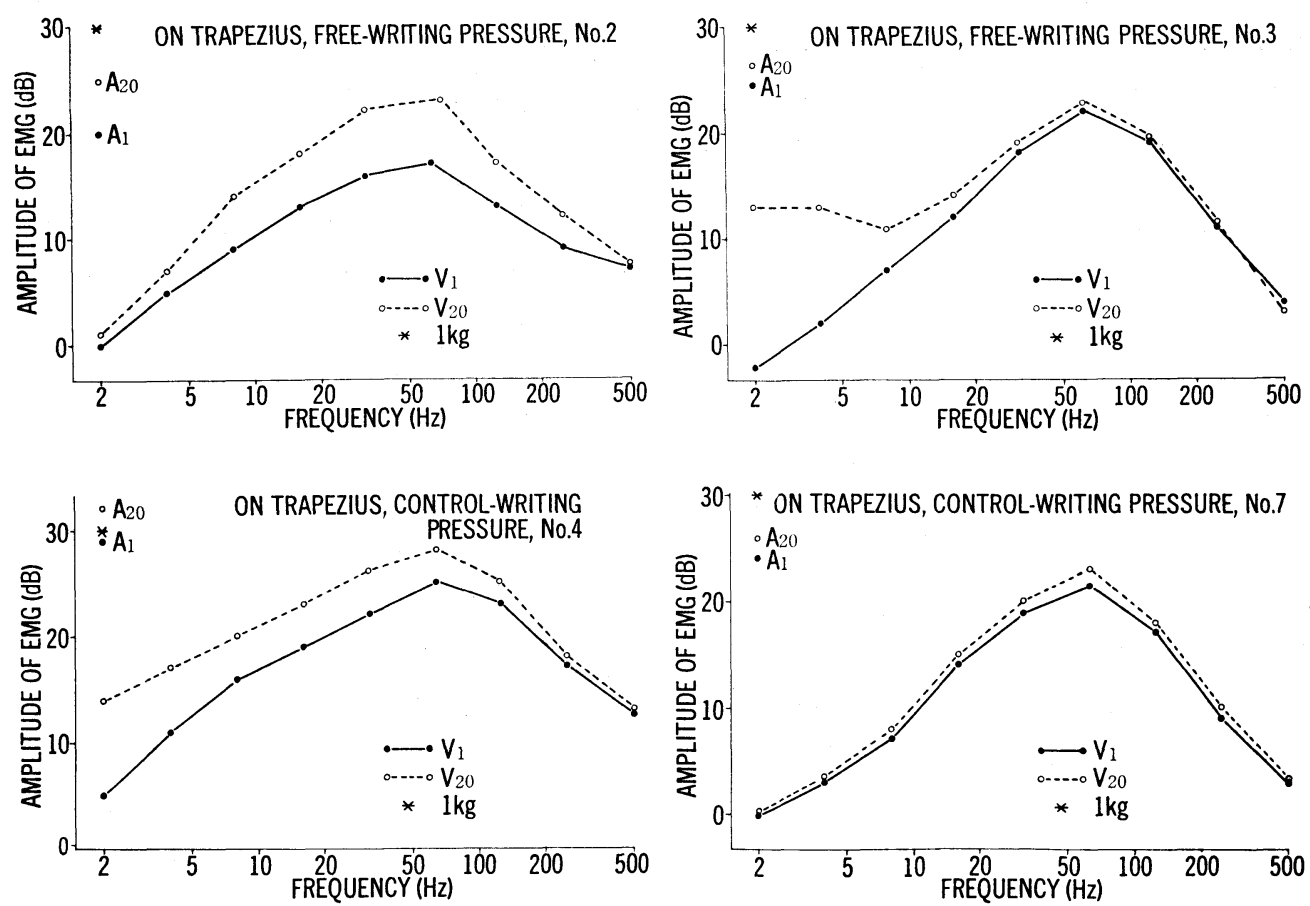

Figs. 2, a, b, c and $d$ : The frequency spectra of the EMG on the trapezius muscles for the hear-writing at $1 \mathrm{~min}$ and $20 \mathrm{~min}$. The discharge of EMG for holding 1 $\mathrm{kg}$ is adopted as the standard at $30 \mathrm{~dB}$ for each subject. The overall values at the $1 \mathrm{~min}$ and $20 \mathrm{~min}$ are also shown. The spectra regarding the four subjects ( $a, b, c$ and $d$ ) are plotted as the typical examples and beside, the spectra under the free-writing pressure show in $a$ and $b$, and those under the control-writing pressure in $\mathrm{c}$ and $\mathrm{d}$.

different conditions as indicated with the entry of experiment in Table 1, the tendency of the spectrum change of EMG can be clearly grasped by them. The spectra of the other subjects which are not shown in the figures have similar tendency. The spectra of the trapezius denote a peculiar pattern with one peak near $60 \mathrm{~Hz}$, while some of those of flexor show the peak frequency shift to the higher frequency. There are some cases that remarkable difference occurs on the spectra between $V_{1}$ and $V_{20}$ below $20 \mathrm{~Hz}$, especially on the trapezius. On the other hand, almost all cases of the spectra of $V_{1}$ 


\section{MƯSCỦLAR BỦRDËN DERIVED FROM D̉ÝNAMMIC LOADÉING I}
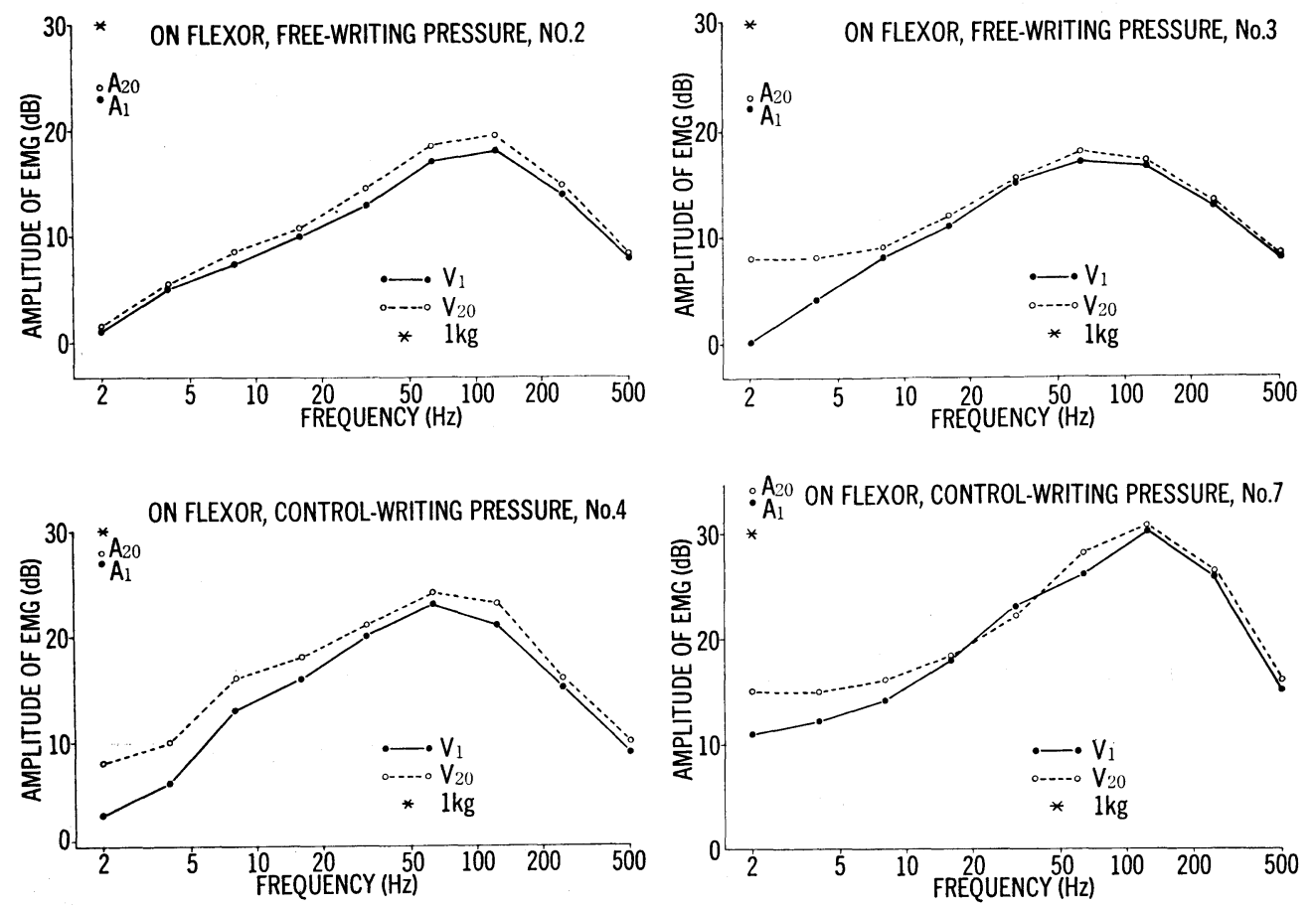

Figs. 3, a, b, c and d: The frequency spectra of the EMG on the forearm flexor muscles for the hear-writing. The figures of $a$ and $b$ show the results under the free-writing pressure and those of $\mathrm{c}$ and $\mathrm{d}$ the results under the control-writing pressure.

and $\mathrm{V}_{20}$ above $60 \mathrm{~Hz}$ are similar or have a little difference. The points regarding the increase of muscular tension assumed from the increase of the discharge of EMG in the low frequency observed on the trapezius are the essential nature for the writing performance which means the excitation by continuous dynamic force to the muscles.

Taking this fact into consideration, the output voltage of the EMG was analyzed statistically. The rectified levels of the EMG of overall frequency, their components below and above $20 \mathrm{~Hz}$ are called $\mathrm{A}, \mathrm{L}$ and $\mathrm{H}$. The average values of EMG within $4 \mathrm{~min}$ for each subject at the initial and the last periods of the writing work are indicated with 1 and $20 \mathrm{~min}$ in subscripts like $\mathrm{A}_{1}, \mathrm{~A}_{20}, \mathrm{~L}_{1}, \mathrm{~L}_{20}, \mathrm{H}_{1}$, and $\mathrm{H}_{20}$. The variance analysis are tried not only on these items separately, but also on $\left(A_{20}-A_{1}\right),\left(L_{20}-L_{1}\right)$, $\left(\mathrm{H}_{20}-\mathrm{H}_{1}\right)$ and $\left(\left(\mathrm{L}_{20}-\mathrm{H}_{20}\right)-\left(\mathrm{L}_{1}-\mathrm{H}_{1}\right)\right)$. As these values are in $\mathrm{dB}$, the $\mathrm{dB}$ value is converted to the real quantity for the variance analysis. The value of $\left(\mathrm{L}_{20}-\mathrm{L}_{1}\right)$ in $\mathrm{dB}$ means the ratio of $\mathrm{L}_{20}$ to $\mathrm{L}_{1}$.

\section{The trapezius}

With the trapezius on the writing hand side, the entry of $\left(\mathrm{L}_{20}-\mathrm{L}_{1}\right)$ alone becomes significant for each factor in the variance analysis at the significant level $0.05\left(^{*}\right)$ or $\left.0.01{ }^{* *}\right)$ as shown in Table 2. The positive value of $\mathrm{L}_{20}-\mathrm{L}_{1}$ means the increase of muscular tension in the low frequency components below $20 \mathrm{~Hz}$ during the writing. 


\section{T. SAKURAI AND T. MIWA}

Table 2. The rectified voltage of the EMG on the right trapezius $\left(\mathrm{L}_{20}-\mathrm{L}_{1}\right)$. $\mathrm{T}$ : total sum of variance, $\mathrm{e}$ : error, $\mathrm{SS}$ : variance of factors, $\mathrm{df}$ : degree of freedom, $\mathrm{SS}_{\mathrm{e}}$ : variance of error.

The variance associated with the factors $A \times B$ and $B \times C$ are so small that they are summed up into the e. This table was obtained with the experiments on 16 subjects.

\begin{tabular}{l|rrrr|rrrr}
\hline & \multicolumn{3}{|c|}{ Free-writing Pressure } & \multicolumn{3}{c}{ Control-writing Pressure } \\
\cline { 2 - 8 } & $\mathrm{SS}$ & $\mathrm{df}$ & $\mathrm{F}\left(\mathrm{SS} / \mathrm{SS}_{\mathrm{e}} / \mathrm{df}_{\mathrm{e}}\right)$ & $\mathrm{Test}$ & $\mathrm{SS}$ & $\mathrm{df}$ & $\mathrm{F}\left(\mathrm{SS} / \mathrm{SS}_{\mathrm{e}} / \mathrm{df}_{\mathrm{e}}\right)$ & $\mathrm{Test}$ \\
\hline $\mathrm{A}$ & 0.9653 & 1 & 9.2917 & $\star$ & 0.3335 & 1 & 26.5619 & $\star \star$ \\
$\mathrm{B}$ & 0.0946 & 1 & 0.9106 & & 0.1743 & 1 & 13.8823 & $\star \star$ \\
$\mathrm{C}$ & 0.0352 & 1 & 0.3388 & & 0.0053 & 1 & 0.4221 & \\
$\mathrm{D}$ & 0.0039 & 1 & 0.0375 & & 0.0000 & 1 & 0.0000 \\
$\mathrm{~A} \times \mathrm{C}$ & 0.2678 & 1 & 2.5778 & & 0.0046 & 1 & 0.3664 \\
$\mathrm{~d}$ & 0.9073 & 1 & & & 0.2233 & 1 & \\
$\mathrm{~T}$ & 3.2091 & 15 & & & 0.8540 & 15 & \\
$\mathrm{e}$ & 0.9350 & 9 & & 0.1130 & 9 & \\
\hline
\end{tabular}

The factor which is significant in the variance analysis is summed up on the level of 0 and 1 separately, referring the orthogonal array table and their averaged values are shown in Table 5. The effect of the factor means the difference of the values observed between its level of 0 and 1 .

On the free-writing pressure, the kinds of writing tools alone become significant and the ball-point pen shows higher EMG (1.476) than that by the pencil (0.985) (Table 5). The muscular tension judged by EMG caused by using the ball-point pen increases by about $50 \%$ as compared with the pencil. The confidence interval of these values are also tabulated in the same table. On the control-writing pressure, the kinds of writing tools and the diameters of pen holders are simultaneously significant. The ball point pen give an influence more severely by about $30 \%$ than the pencil. The same results seen on the free and the control-writing pressure may come from the fact that the ballpoint pen touches the paper by the solid metal top covered with ink without changing the touching cross-section, but the pencil touches more softly by the top with the variable cross-section. The effects of the $11 \mathrm{~mm}$ diameter of holder are severer by about $20 \%$ than that of the $7 \mathrm{~mm}$ diameter of the holder. Enlargement of a diameter of the holder grows the muscular tension of the trapezius to ensure gripping of the writing tool. It may be suggested that the optimum diameter may exist below $11 \mathrm{~mm}$, but it is hard to fix the value by the muscular tension observations alone.

\section{The forearm flexor}

On the free-writing pressure, there is no sign of $*$ in the variance analysis table of the EMG on the writing hand side on entire items of calculation. On the controlwriting, however, only the factor of diameters of the writing tools are significant with 


\section{MUSCULAR BURDEN DERIVED FROM DYNAMIC LOADING I}

Table 3. The rectified voltage of the EMG on the right flexor $\left(A_{20}-A_{1}\right)$. The variances of the factors $A \times B$ and $A \times C$ are summed up into the e. This table was obtained with the experiments on 16 subjects.

\begin{tabular}{l|cccc|cccc}
\hline & \multicolumn{3}{|c|}{ Free-writing Pressure } & \multicolumn{4}{|c}{ Control-writing Pressure } \\
\cline { 2 - 8 } & $\mathrm{SS}$ & $\mathrm{df}$ & $\mathrm{F}\left(\mathrm{SS} / \mathrm{SS}_{\mathrm{e}} / \mathrm{df}_{\theta}\right)$ & $\mathrm{Test}$ & $\mathrm{SS}$ & $\mathrm{df}$ & $\mathrm{F}\left(\mathrm{SS} / \mathrm{SS}_{\mathrm{e}} / \mathrm{df}_{\mathrm{e}}\right)$ & $\mathrm{Test}$ \\
\hline $\mathrm{A}$ & 0.0324 & 1 & 0.3025 & 0.0030 & 1 & 0.2328 & \\
$\mathrm{~B}$ & 0.0012 & 1 & 0.0112 & 0.0784 & 1 & 6.0834 & $\star$ \\
$\mathrm{C}$ & 0.3721 & 1 & 3.4739 & 0.0506 & 1 & 3.9263 & \\
$\mathrm{D}$ & 0.1806 & 1 & 1.6861 & 0.0001 & 1 & 0.0078 & \\
$\mathrm{~A} \times \mathrm{C}$ & 0.0462 & 1 & 0.4313 & 0.0484 & 1 & 3.7556 & \\
$\mathrm{~B} \times \mathrm{C}$ & 0.0144 & 1 & 0.1344 & 0.0506 & 1 & 3.9263 & \\
$\mathrm{~d}$ & 0.1056 & 1 & & 0.0016 & 1 & \\
$\mathrm{~T}$ & 1.6094 & 15 & & 0.3358 & 15 & \\
$\mathrm{e}$ & 0.8569 & 8 & & & 0.1031 & 8 & \\
\hline
\end{tabular}

regard to $A_{20}-A_{1}$ as shown in Table 3. In this case, the $11 \mathrm{~mm}$ diameter holder has also greater effect of about $10 \%$ in the overall value on the muscles than the $7 \mathrm{~mm}$ diameter holder like on the trapezius. The larger diameter of the holder also is not suitable in this case.

\section{The Muscular tension}

The muscular tension for holding the weight which means the static load is compared with that for writing performance which means the dynamic load. To investigate the EMG of the flexor, the weight was set on the palm of one hand of which the forearm was held horizontally in front of the body. To examine the EMG of the trapezius, the arm was stretched straightforward on the same level of the shoulder and the weight was set on its palm. The linearity between the weights and the rectified output voltage of the EMG ( $6 \mathrm{~dB} / 2$-fold weight) nearly exists with the flexor. On the other hand, the linearity for the trapezius is not so good by about $4 \mathrm{~dB} / 2$-fold weight. The lack of linearity of the output voltage of the trapezius depends upon the dead weight of the arm and the difference of contribution rate of the muscles to the action of holding hand. The comparison of muscular tension between the static and the dynamic loads, however, is convenient to compare quantitatively the effects on the same muscles derived from the different stimulus. The rectified voltage of $\left(A_{20}\right)$ of the flexor on the free-writing pressure corresponds to that for holding of the weight of $0.56 \pm 0.296 \mathrm{~kg}$ (average and standard deviation on 16 subjects) and it does $0.85 \pm 0.354 \mathrm{~kg}$ for the control-writing pressure. On the trapezius, provided the linearity is assumed, the muscular discharge for the free-writing pressure corresponds to that for holding $0.65 \pm 0.355 \mathrm{~kg}$ and for the control-writing pressure, it corresponds to that for holding $0.91 \pm 0.326 \mathrm{~kg}$.

K. Kogi ${ }^{11)}$ and D. B. Chaffin ${ }^{12,13)}$ reported that the long static muscle work like holding the weight caused the increase of discharge of the EMG, especially the increase 


\section{T. SAKURAI AND T. MIWA}

of low frequency components in the EMG. This fact is recognized even on the continuous dynamic load of the muscles as the writing performance. Moreover, they said the increase of the muscular tension for holding the weight derived the muscular fatigue. This conclusion may be applied to the continuous dydamic use of the muscles.

\section{The ruriting pressure}

The writing pressure shows the spectra with the main frequency range from 1 to $7 \mathrm{~Hz}$ and with the amplitude range from 0.05 to $0.25 \mathrm{~kg}$ in the free-writing and from 0.13 to $0.50 \mathrm{~kg}$ for the control-writing on each subject. Representative spectra for 2 subjects are shown in Fig. 4. In the hear-writing, the frequency range is determined

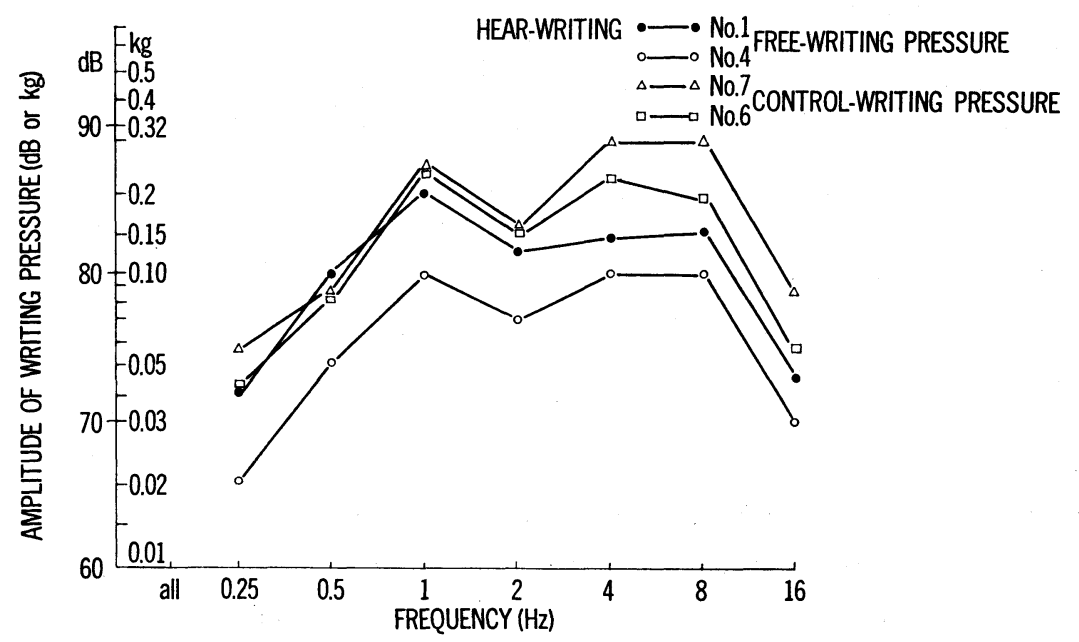

Fig. 4: Representative frequency spectra of writing pressure on 2 subjects under different experimental conditions. The same subject was asked to try the two different tests of entries of No. 1 and No. 6, and the other to try those of No. 4 and No. 7. The reference of the level of the writing pressure in $\mathrm{dB}$ is adopted as $0.01 \times 10^{-3} \mathrm{~kg}$ (peak-to-peak).

by the speed of writing ( 1 letter/sec) and the number of the lines which construct the letter. As our force pickup was possible to measure from $1 \mathrm{~Hz}$, the data shown with the dotted lines in Fig. 4 were observed with an instrument which was constructed by a cantilever applied on the strain gage. The output of the gage was recorded with a pen-writing recorder to read peak-to-peak value and the instrument was calibrated by the weight. Since the low frequency components below $1 \mathrm{~Hz}$ were not included in the main spectrum, the force pickup of thin polymer film was used to measure the overall value for the writing pressure.

The variance analysis was made on the overall value of the force pickup for the writing. Although $A_{1}, A_{20}$, and $A_{20}-A_{1}$ were calculated, the factors regarding the $A_{20}$ alone are significant for both the cases of the free-writing and the control-writing as 


\section{MUSCULAR BURDEN DERIVED FROM DYNAMIC LOADING I}

Table 4. The writing pressure $\left(A_{20}\right)$. The variances of the factors $A \times B$ and $\mathrm{B} \times \mathrm{C}$ are summed up into the e. This table was obtained with the experiments on 16 subjects.

\begin{tabular}{|c|c|c|c|c|c|c|c|c|}
\hline & \multicolumn{4}{|c|}{ Free-writing Pressure } & \multicolumn{4}{|c|}{ Control-writing Pressure } \\
\hline & SS & $\mathrm{df}$ & $\mathrm{F}\left(\mathrm{SS} / \mathrm{SS}_{\mathrm{e}} / \mathrm{df}_{\mathrm{e}}\right)$ & Test & SS & df & $\mathrm{F}\left(\mathrm{SS} / \mathrm{SS}_{\mathrm{e}} / \mathrm{df}_{\mathrm{e}}\right)$ & Test \\
\hline A & 0.6162 & 1 & 13.8958 & $\star \star \star$ & 1.3865 & 1 & 8.4002 & $\star$ \\
\hline B & 0.0042 & 1 & 0.0947 & & 1.1610 & 1 & 7.0340 & $\star$ \\
\hline $\mathrm{C}$ & 0.4356 & 1 & 9.8231 & $\star$ & 1.3631 & 1 & 8.2584 & $\star$ \\
\hline $\mathrm{D}$ & 0.0009 & 1 & 0.0203 & & 0.0023 & 1 & 0.0139 & \\
\hline $\mathrm{A} \times \mathrm{C}$ & 0.0110 & 1 & 0.2481 & & 1.5939 & 1 & 9.6567 & $\star$ \\
\hline $\mathrm{d}$ & 0.0030 & 1 & & & 0.4523 & 1 & & \\
\hline $\mathrm{T}$ & 1.4700 & 15 & & & 7.4446 & 15 & & \\
\hline e & 0.3991 & 9 & & & 1.4855 & 9 & & \\
\hline
\end{tabular}

denoted in Table 4. The kinds of tools and the number of sheets of paper are significant for both the writing pressure. Furthermore, the diameters of the holder and the interactions between the kinds of tools and the sheets of paper become significant in the control-writing. It attracts our attention on Table $5, \mathrm{c}$ that the free-writing pressure of the pencilis (1.981) is larger than that of the ball-point pen (1.589). but the controlwriting pressure of the ball-point pen (2.093) is larger than that of the pencil (1.504). Under the free-writing pressure, the subject is apt to press the paper by the pencil more strongly than by the ball-point pen. On the contrary, when the subject is asked to

Table 5. The averages of each level of the factors which becom significant in the variance analysis. Confidence coefficient is $95 \%$.

\begin{tabular}{|c|c|c|c|c|c|c|c|}
\hline & & & & \multicolumn{2}{|r|}{0} & \multicolumn{2}{|r|}{1} \\
\hline & & & & Mean & $\begin{array}{l}\text { Confidence } \\
\text { limits } \\
(95 \%)\end{array}$ & Mean & $\begin{array}{c}\text { Confidence } \\
\text { limits } \\
(95 \%)\end{array}$ \\
\hline \multirow{3}{*}{$\mathbf{a}$} & \multirow{3}{*}{ Trapezius $\mathrm{L}_{20}-\mathrm{A}_{1}$} & Free-writing & A & 1.476 & \pm 0.450 & 0.985 & \pm 0.147 \\
\hline & & \multirow{2}{*}{ Control-writing } & A & 1.273 & \pm 0.172 & 0.984 & \pm 0.150 \\
\hline & & & B & 1.024 & \pm 0.132 & 1.233 & \pm 0.225 \\
\hline b & Flexor $A_{20}-A_{1}$ & Control-writing & B & 0.975 & \pm 0.085 & 1.115 & \pm 0.136 \\
\hline \multirow{6}{*}{ c } & \multirow{6}{*}{ Writing pressure $A_{20}$} & \multirow{2}{*}{ Free-writing } & A & 1.589 & \pm 0.229 & 1.981 & \pm 0.181 \\
\hline & & & $\mathrm{C}$ & 1.620 & \pm 0.273 & 1.950 & \pm 0.170 \\
\hline & & \multirow{4}{*}{ Control-writing } & A & 2.093 & \pm 0.644 & 1.504 & \pm 0.436 \\
\hline & & & B & 1.529 & \pm 0.433 & 2.068 & \pm 0.663 \\
\hline & & & $\mathrm{C}$ & 1.506 & \pm 0.270 & 2.090 & \pm 0.731 \\
\hline & & & $\mathrm{A} \times \mathrm{C}$ & 1.483 & \pm 0.225 & 2.114 & \pm 0.629 \\
\hline
\end{tabular}




\section{T. SAKURAI AND T. MIWA}

press the paper by the force stronger than the given minimum pressure $(0.13 \mathrm{~kg})$, he seems to press the paper more strongly with the ball-point pen than with the pencil.

On the factor of the diameter of holder, the writing pressure of the $11 \mathrm{~mm}$ diameter is stronger than that of the $7 \mathrm{~mm}$ diameter, so that the larger diameter may consume the human energy. This fact supports the results observed on the EMG of the trapezius and the flexor. The subjects press more strongly, if the sheets of paper is thicker, under both the free-writing and the control-writing pressure.

The interaction effect of the combination of (the ball-point pen +1 sheet of paper) and (the pencil +3 sheets of paper) on the control-writing pressure (1.483) is smaller than that of the combination of (the ball-point pen +3 sheets) and (the pencil +1 sheet of paper) (2.114) (Table 5, c). From the viewpoint of the writing pressure, the combination of the ball-point pen and the sheets of paper may give considerably large amount of interaction effect than the effect caused from the other factors. The effect of this interaction can be seen in the practical writing of copy slips.

Finally, the free-writing pressure and the control-writing pressure are taken as one of the factors mentioned above and are assigned to the orthogonal array table $\mathrm{L}_{16}\left(2^{15}\right)$ with repetition. On the values of $\mathrm{A}_{20}$, the control-writing pressure indicater to be larger in the values of the factors than the free-writing pressure. The other parts agree with the results described previously.

For the correlation matrix calculated with the flexor, the trapezius and the writing pressure, the flexor is significantly related to the writing pressure by about $0.4^{*}$ checked by $\mathrm{T}$-test $\left(0.05^{*}\right)$. The trapezius has smaller relation to the writing pressure by about 0.24 without significance and the trapezius does not have clear relation with the flexor.

\section{ConClusion}

1) On the muscles of the trapezius and of the foream flexor (flexor), their tension caused by the hear-writing ( 1 letter/sec) is always severer than that by the see-writing.

2) The writing performance under the control-writing pressure above $0.13 \mathrm{~kg}$ has harder effect on the muscles observed than that under the free-writing pressure.

3) In the hear-writing, the amplitude in the low frequency components on the trapezius and overall values on the flexor in the beginning stage increase as compared with those in the end stage under the both pressures of the free-writing and the controlwriting. The ball-point pen and the $11 \mathrm{~mm}$ diameter of pen-holder in the control writing promote severely the muscular tension on the trapezius as compared with the pencil and the $7 \mathrm{~mm}$ diameter of pen-holder.

4) The muscles of flexor may not be used severely during the writing work and leave margin in their capacity. In the hear-writing on the flexor, the increase of the holder's diameter alone becomes significant to the effect on the increase of muscular tension under the control-writing pressure.

5) The writing pressure shows the spectra in the frequency range from 1 to $7 \mathrm{~Hz}$ 


\section{MUSCULAR BURDEN DERIVED FROM DYNAMIC LOADING I}

and the amplitude range is $0.05 \sim 0.25 \mathrm{~kg}$ for the free-writing pressure and $0.13 \sim 0.50 \mathrm{~kg}$ for the control-writing pressure. The kinds of writing tools and the sheets of paper under both the writing pressures and, moreover, the holder's diameter and the interaction between the kinds of writing tools and the number of sheets of paper under the control-writing pressure become significant in the variance analysis of the writing pressure.

6) The discharge of EMG of the flexor under the free-writing pressure corresponds to that generated holding the weight of about $0.5 \mathrm{~kg}$ on the palm of one hand of which the forearm was held horizontally in front of the body and that under the controlwriting pressure corresponds to about $0.9 \mathrm{~kg}$. When the discharge of EMG of the trapezius is compared with that generated from holding the weight on the palm of which the arm was stretched straightforward on the same level of shoulder, the equivalent weight is about $0.7 \mathrm{~kg}$ for the free-writing pressure and it is about $0.9 \mathrm{~kg}$ for the control-writing pressure.

\section{ACKNOWLEDGement}

The authors wish to express their gratitude for the guidance and encouragement received from Dr. H. Sakabe and Dr. M. Takamatsu. They also wish to express their thanks to the members of National Institute of Industrial Health who achieved the experiments as the subjects.

\section{REFERENCES}

1) Kretchmer, H. C. E. (1953). Schweiz. Ges. Psychiatr., 71, Heft 1/2.

2) Pascal, G.R. (1943). Charact. Pers. 12, 123.

3) Kao, H.S. R., Smith, K. U. and Knutson, R. K. (1969). Ergonomics, 12, 435.

4) Yasuhara, M. (1974). Jap. J. Med. Elect. Biol. Eng. 12, 69.

5) Shigeta, S. (1973). Rodo Eisei 14, 50. (in Japanese)

6) Maeda, K. (1975). Jap. J. Ind. Health, 17, 203. (in Japanese)

7) Kimura, T. (1971). Jikken Keikaku no Tebiki (Introduction to Experimental Designs) Nankodo, Tokyo. (in Japanese)

8) Ohmura, T. and Imada, N. (1972). Suisoku Tokei no Fortran (Fortran Programs for Statistics) Ohm-Sha, Tokyo. (in Japanese)

9) Shimada, S. (1972). Chokko Hairetsu no Hanashi (Introduction to Orthogonal Arrary) Nihon Kikaku Kyokai, Tokyo. (in Japanese)

10) Kishine, T. (1969). Tokeigaku (Statistics) 316, Yokendo, Tokyo (in Japanese)

11) Kogi, K. and Hakamada, T. (1962). J. Labour Sci. 38, 519.

12) Chaffin, D. B. (1973). J. Occup. Med. 15, 346.

13) Chaffin, D. B. (1969). J. Occup. Med. 11, 109. 